\title{
Direct Payments in England: Factors Linked to Variations in Local Provision
}

\section{JOSÉ-LUIS FERNÁNDEZ*, JEREMY KENDALL**, VANESSA DAVEY*** and MARTIN KNAPP***}

\author{
*Contact author: Personal Social Services Research Unit (PSSRU), London School of \\ Economics, Houghton Street, London WC2A $2 A E$ \\ email: j.fernandez@lse.ac.uk. \\ ** Formerly at PSSRU, London School of Economics. Now at School of Social Policy, \\ Sociology and Social Research, University of Kent at Canterbury \\ ***PSSRU, London School of Economics
}

\begin{abstract}
Direct payments have moved to the heart of the government's drive for increased user choice. At the same time, implementation has remained disappointing. This article explores the demand, supply and related factors associated with patterns of local variability in uptake and intensity of care package provision. Statistical analyses are conducted for key client groups people with physical disabilities, older people, people with learning disabilities and people who use mental health services - using data for England from 2000-01 to 2002-03. The results suggest that direct payments variability reflects a complex array of factors, both within and beyond the control of local public actors. In particular, while local policy preferences appear to shape the extent of direct payments growth, the results also demonstrate that understanding levels of activity requires attention to local circumstances.

I see direct payments, personal cash budgets, and other ways of extending choice and control as key to developing social care for the twenty-first century (Parliamentary Under Secretary of State for Community Care, Department of Health, 2004).
\end{abstract}

\section{Introduction}

Recently reinforced by the energy behind the government's 'choice' campaign, the policy of direct payments (user-controlled purchasing of social care) has been catapulted high up the social care agenda. As policy makers have adjusted and broadened the ambit of the direct payments approach, policy commentators have widened their descriptions of its contours and potential implications.

While researchers have begun to elaborate more sophisticated explanations for the overall trajectory of developments, research on local patterns has been relatively limited, despite considerable variations in the introduction, take-up and level of direct payments. One purpose of this article is to chart those variations. A second is to apply statistical modelling to try to explicate socio-economic, political and policy process factors associated with these variations in England. 


\section{Policy background}

\section{Origins and policy salience}

A superficial glance at the timing and content of social care primary legislation in England and Wales would suggest that direct payments policy has been in place for less than a decade. It is indeed true that, packaged and recognised as such, direct payments date from the second half of the 199os, but the core idea of consumer-directed services has a longer policy pedigree. The Independent Living Fund was established in the late 1980s as a compensatory source of funds for people with disabilities adversely affected by ongoing social security reforms (Glasby and Littlechild, 2002; Barnes et al., 2004). Its take up as high as 22,000 people in 1993 - significantly exceeds current numbers for direct payments (see below). Moreover, as early as the first half of the 1980s, some local authorities were experimenting with 'third-party payment' and 'indirect' schemes in which cash reached the user via an intermediary body, typically in the voluntary sector.

While recent critiques of the limited roll out of direct payments have often pointed to local social services departments' limitations as obstacles (e.g. Glasby and Littlechild, 2002; Spandler, 2004), it should be acknowledged that it was a combination of local social work enthusiasm and local political commitment that made these policies possible in the first place. These earlier manifestations of policy at different levels of government were themselves, to a significant degree, a response to voluntary sector pressure - including from groups controlled by users for policies to support 'independent living' and 'empowerment'. These arguments in turn had their origins in the disabled people's social movements, which gathered momentum from the 1970 (Barnes, 2004). The New Labour emphasis on mobilising voluntary sector and user groups to help diffuse and implement policy, through the Direct Payments Development Fund, thus built on the legacy of a quarter of a century of pioneering collaboration between voluntary sector groups as advocates and implementers, supported by local government allies.

Yet it has only been since the second half of the 1990s that direct payments have moved centre stage, in aspiration if not yet in practical achievement. The Community Care (Direct Payments) Act 1996 was clearly central in allowing user-controlled purchasing for people with physical disabilities, since which time the arrangements have been extended to other groups of service users. Since 2000 this extension has included older people, with potentially enormous resource consequences for England's social care system, and since 2005 there has been parallel emphasis on individual budgets. Consolidating and comprehensive central government guidance has sought to encourage and steer at a 'technical' implementation level, while, yet more significantly, it is now beholden on all local councils in England and Wales to roll out the approach. Not only has it become mandatory, via secondary legislation, for councils to offer payments to all 'suitable' users, but also the numbers of people in receipt of direct payments chave been built into the national system for monitoring 'performance'. 
What lies behind this step change in the policy salience of direct payments? A number of developments are relevant. First, within professional discourse, the philosophical strand emphasising 'independent living' - and seeing cash payments as an appropriate response - has moved closer to a central position within social work theory, where it goes with the grain of wider trends in thought (Harris, 1999). Enthusiasm for cash benefits in lieu of services also has considerable normative credibility overseas (Kodner, 2003; Ungerson, 2004). Second, it is only relatively recently that a belief has grown that the policy can be cost-effective, although the evidence used to promote that argument goes back further (Zarb and Nadash, 1994; Dawson, 2000). Third, the policy appeals across the political spectrum (Spandler, 2004). Conservative commentators can applaud its market-like characteristics, while for New Labour the policy resonates neatly with the broader thrust of the choice in public services campaign. Its apparent popularity with social care constituencies presents itself as an electoral asset, reaching well beyond traditional political heartlands to large numbers of older voters, for example. The policy also seems to be remarkably popular with those users who have secured access to it, as reported enthusiastically by its promoters (Hasler et al., 2000; Hasler and Stewart, 2004a, 2004b).

Direct payments policy can additionally present itself as a way to offer care and support to people whose needs are situated in the 'grey' area between social and health care (Lewis, 2001). Empowering users cuts through at least some of the supply-side boundary disputes and role conflicts that have traditionally dogged this area (Glendinning et al., 2000a, 200ob). And while recent court rulings and Department of Health statements have placed the direct purchase of health-oriented services out of scope (see Glasby, 2004), there are still 'grey' activities with a mixture of health and social care attributes that are potentially allowable.

Finally, in principle at least, the policy has an attractively simple justification. As noted, it can be defended philosophically by users and professionals alike, and has massive political appeal. More than this, it can be communicated straightforwardly as 'common sense'. In the cut and thrust of public policy as a whole, it therefore resonates with the current government's wish to present and promote policies easy to understand and represent to the media. Within the specialist social care professional community, the policy appeals strongly to national inspectorates looking for simple 'messages' which apply across otherwise fragmented local authority and client group audiences (Social Services Inspectorate, 2003; Commission for Social Care Inspection, 2004a).

\section{The rhetoric-reality gap}

Given this extraordinary combination of historical, philosophical, practical, economic and political advantages, it might be anticipated that direct payments would, by now, be successfully bedding down across the country. The reality is 


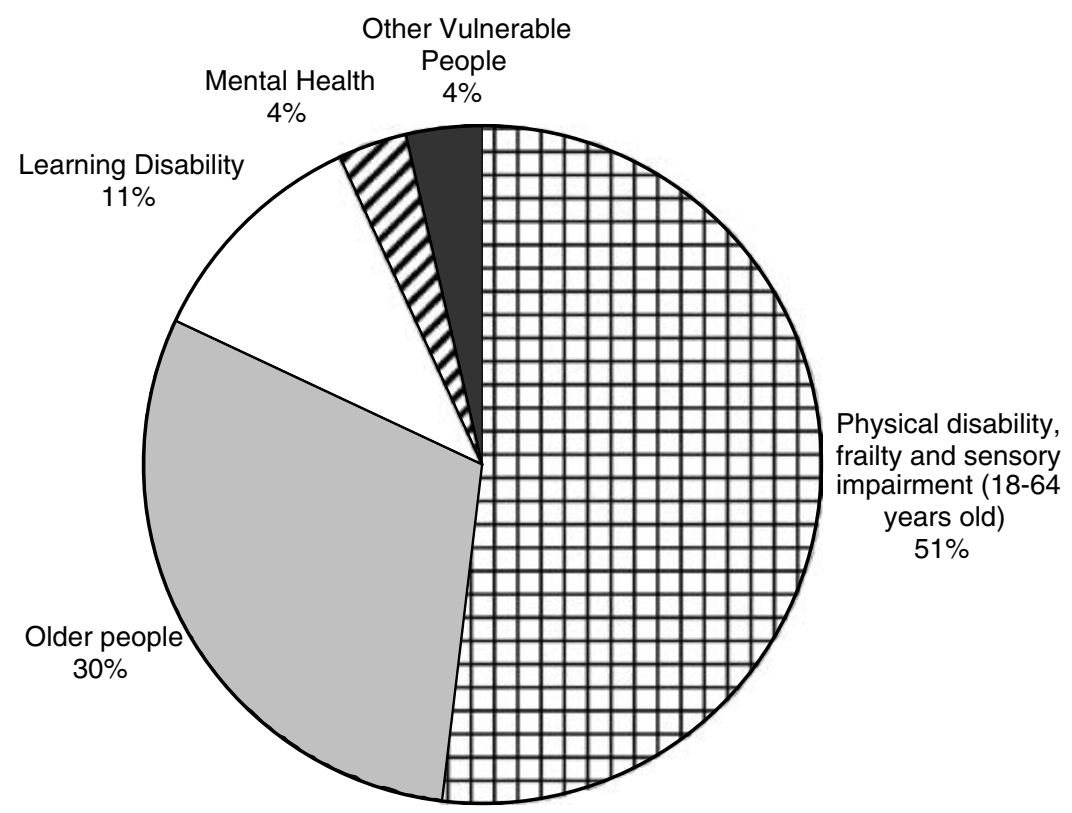

Figure 1. Distribution of direct payment packages by client type (England, 1 April 2003 to 31 March 2004).

Source: RAP returns, Department of Health.

very different; diffusion of the policy has been much slower than hoped, with just 17,300 adults accessing the scheme in 2003-04, the latest year for which data are available (Department of Health, 2005).

Take-up varies between service user groups (Figure 1). In absolute terms takeup has been low for people with mental health problems (4 per cent of all people with direct payments), and carers and people with learning disabilities (11 per cent). Other take-up rates are relatively low compared with their potential: for people with sensory or physical disability - the star performer in absolute terms with a legislative head start of five years and a particularly supportive national user movement - the rate in 2004 was still only 4.7 per cent of community care users. Presumably, not least because of their overall economic (and political) significance, the poor 'performance' in relation to older people has also caused concern (Commission for Social Care Inspection, 2004a).

Generating as much interest as client group variation has been the extraordinary range geographically. Such heterogeneity is illustrated in Figures 2 and 3, which show respectively the overall spread in the prevalence of direct payment packages per 1000 population, and its corresponding spatial distribution by Councils with Social Services Responsibilities (CSSRs). There has been very limited penetration in some localities (Barnes et al., 2004; Commission for Social 


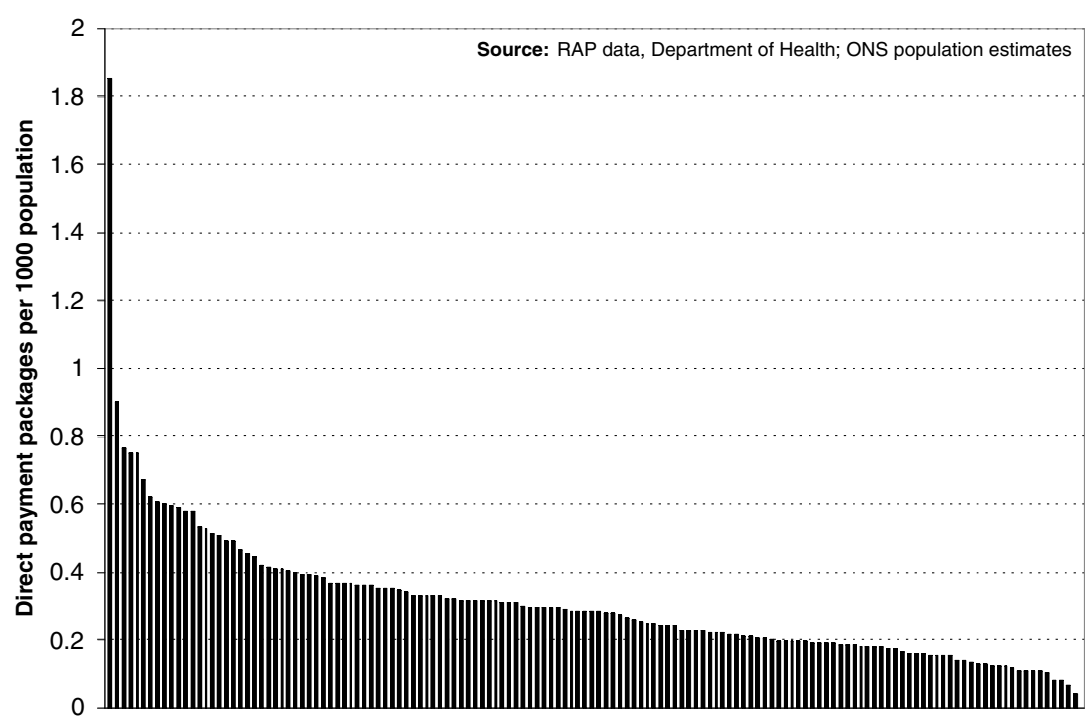

Figure 2. Prevalence of direct payment packages in England, 1 April 2003 to 31 March 2004.

Care Inspection, 2004a). The main purpose of this article is to illuminate the reasons behind the diversity in local implementation.

\section{Towards an understanding of the gap: themes in the literature}

Looking across reports from audit and inspection bodies, the 'trade press' reporting of individual case studies, and more sustained academic and actionresearch locality studies, suggest a number of factors which lie behind these dashed expectations. These 'barriers to implementation' have clearly been more significant than direct payments enthusiasts would initially seem to have assumed. Moreover, these obstacles may not be randomly distributed, but rather concentrated in particular client groups or local authorities, and may therefore help to explain variations in take-up. Several themes dominate current approaches: ${ }^{1}$

- Despite the evident groundswell of strategic support, key front-line actors notably social workers - are simply either not aware of the policy, do not have sufficient information to act, or do not communicate enough about it.

- Where such front-line actors are well informed, 'attitudinal' barriers limit their willingness to support the policy and offer it to users. Typically, such 'attitudes' are not explored or explicated, but sometimes the problem is explicitly attributed to inappropriately high degrees of risk aversion and conservatism (Carmichael and Brown, 2002; Dawson, 2000). 


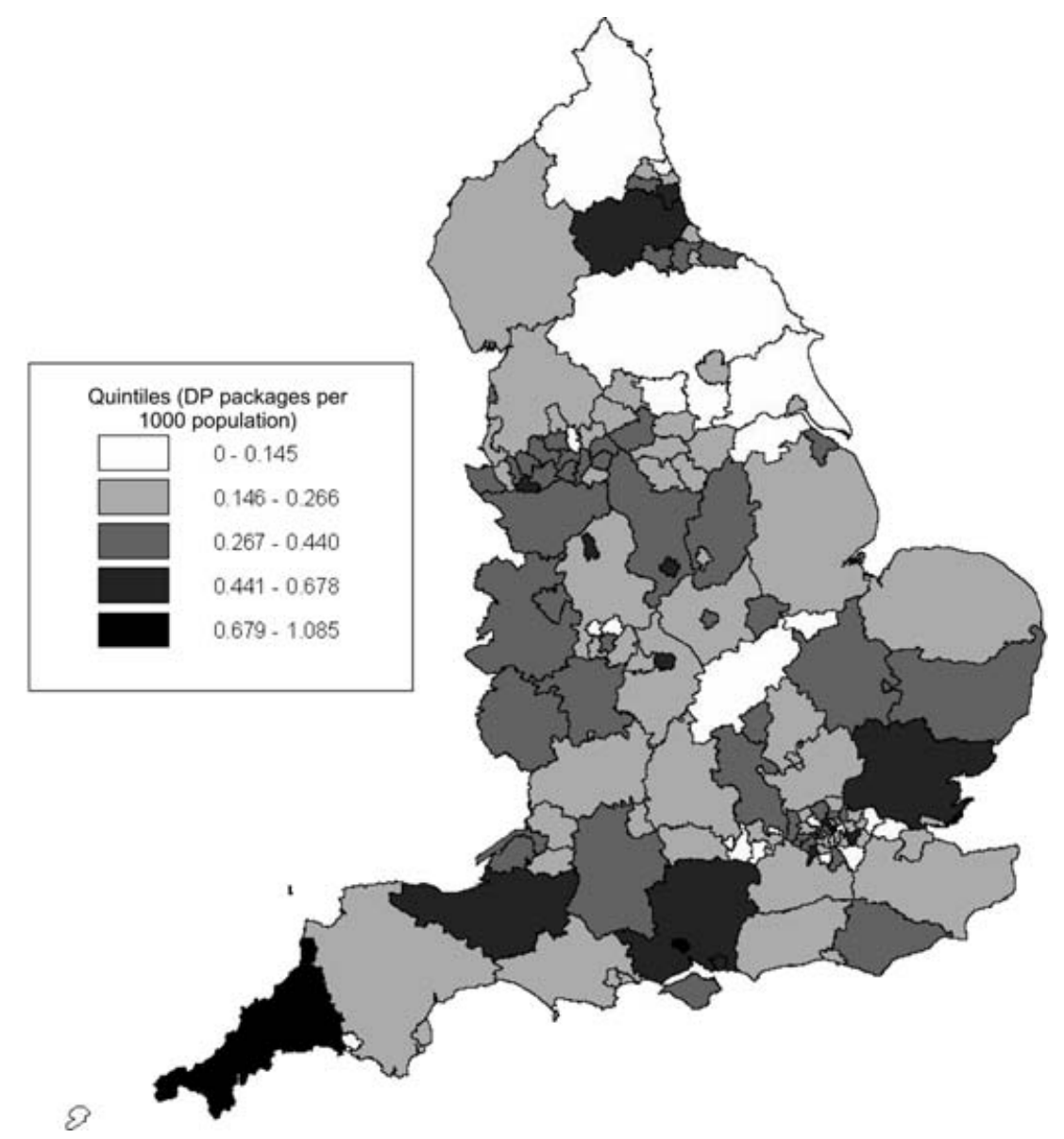

Figure 3. Geographical distribution of direct payment packages per population (quintiles).

- 'Reactionary' or 'vested' interests see the policy's extension as incompatible with their roles and functions. This is protectionism rather than risk aversion. Some commentators point to social workers and, unsurprisingly given their gatekeeping social care role, care managers as key antagonists. For example, care managers holding devolved budgets may be reluctant to relinquish control of these funds to direct payment recipients (Direct Payments Scotland, 2003). Established arrangements may reduce service flexibility, because of long-term commitments to in-house services, or external supply funded by long-term block contracts. More generally, it has been suggested that public service trade unions feel threatened because direct payments redistribute power away from them (Riddell et al., 2005). Or this may be a broader political problem at the departmental or corporate local authority level, associated 
with 'unreconstructed' paternalistic traditions. Professionals may be acting in a less obviously self-interested but still obstructive fashion. For example, finance officers may have legitimate professional concerns about probity and accountability. Front-line care professionals may take the view that the clients with whom they deal, or the social circumstances in which they operate, are respectively too vulnerable and inappropriate for the scheme. This does not mean that these same individuals do not believe direct payments to be appropriate in some/most cases or for some/most client groups, because they may view their users and their circumstances as in some sense 'exceptional'.

- Scarcity of resources is seen as another barrier: the resource rationing processes currently in place within local authorities, in the prevailing fiscal climate, could undermine options in two senses. First, they affect care managers' abilities to offer direct payments at a sufficiently generous level, and hence their willingness to offer them at all. If the current regime is austere, local authorities are tending to respond by tightening eligibility criteria, which in turn means that only the most dependent people qualify for local authority support. If (correctly or incorrectly) it is believed that higher dependency is associated with a lower likelihood of direct payment appropriateness, then these pressures are undermining the feasibility of extending direct payments. Second and relatedly, constraints on local budgets are perceived to limit the capacity to employ personal assistants appropriately. (Personal assistants are the care workers employed directly by users, a key distinctive feature of direct payments compared to traditional services; in the latter, such workers are instead employed by contracted independent providers under external contracting regimes, or directly by public authorities under in-house regimes.)

- Weak or under-developed local voluntary sectors, user groups and/or dedicated ring-fenced support arrangements within councils are seen as generating an insufficiently supportive local policy environment.

- Finally, previous work recognises the role of agency, with development held back by the failure of enthusiastic local leadership to materialise. In suggesting that change can and should be engineered by the introduction of individual 'champions', critics have referred to a failure of policy and political entrepreneurship and support at a sufficiently high level.

The relative weight given to these themes seems to flow from whether the analyst is oriented towards diagnosing the barriers as essentially a 'management' problem, characterised by technical implementation difficulties, or a 'political economy' issue, in which the distribution of power between actors and institutions is centre stage. For the national inspectorates, there is a tendency to emphasise the extent to which difficulties of the former type are at 

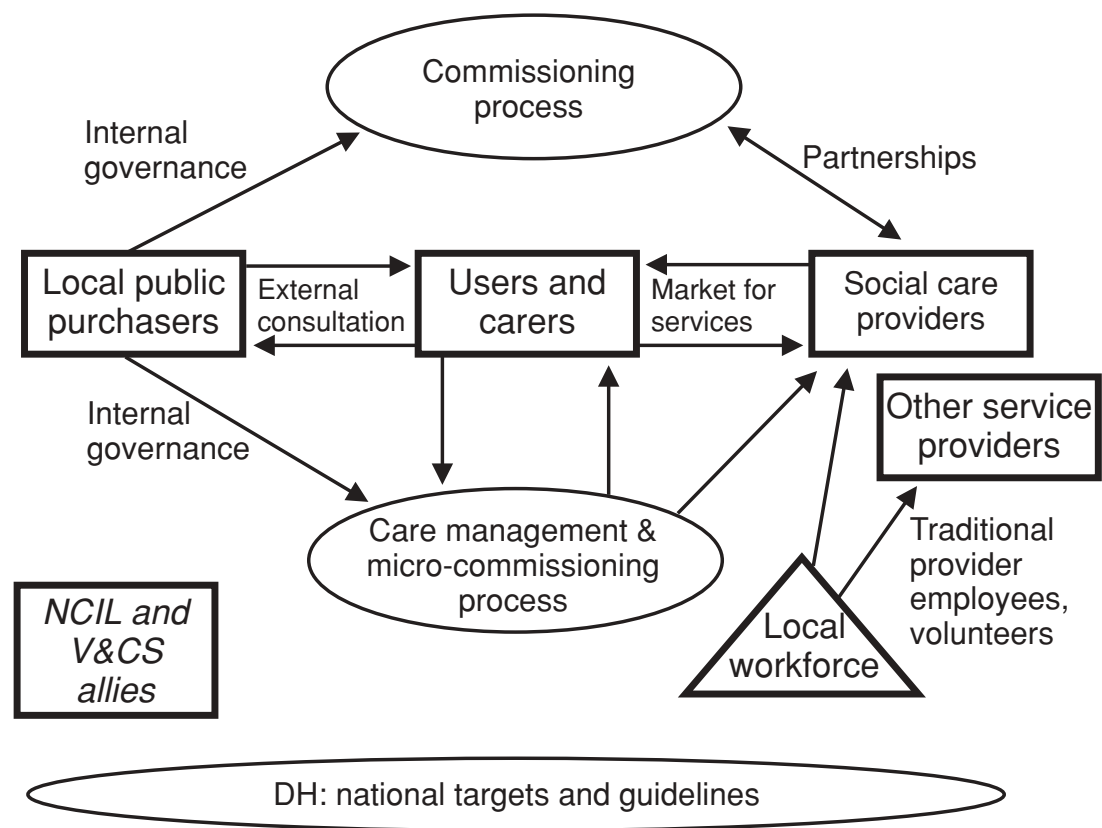

Figure 4. The policy architecture.

stake. Information exchange, system organisation inflexibilities, concomitant 'excessive bureaucracy' and a lack of management leadership are portrayed as keys to understanding 'poor performance' (Commission for Social Care Inspection, 2004a). Other commentators have tended to emphasise wider resource constraints, process complexities, local party political traditions, surfeits of social movement activism and conflicts between the interests of workers, carers and users as the central disabling factors (Glendinning et al., 200oa; Barnes et al., 2004; Spandler, 2004; Riddell et al., 2005).

\section{Variations in direct payments: conceptual and methodological approach the complex policy architecture}

The necessarily elaborate nature of Figure 4 aims to bring home a key point: despite the apparent simplicity of the idea of direct payments, its design and practical implementation are highly complex processes. Establishing arrangements in the first place and then rolling them out in actual delivery involves wide-ranging modifications to the existing architecture of service organisation, as well as introducing completely new elements. Moreover, we need to remember that the processes and relationships represented here have both managerial-technical and political-economic dimensions. So, we should recognise that these components are neither 'policy levers' to be easily pulled, 
nor are they static obstacles to change. Treating the embedding of direct payments in local service systems as reducible to these elements alone is insufficient. The process involves time-consuming argument, persuasion and negotiation at multiple levels, which is not reducible to either mechanistic or political manipulation.

In acting as a map of the main processes and institutions involved in designing and implementing direct payments, and underlining the range of linkages at stake, the figure helps underscore the difficulty of moving from rhetoric to implementation. ${ }^{2}$ The 'barriers' pointed to in the literature are not discrete obstacles which can readily be tackled separately, but are situated within a dense web of inter-dependent institutional relationships and political and economic resource dependencies. This complexity calls for multiple research approaches, as we discuss later.

\section{A model to represent variations}

The unit of analysis is the English local authority (CSSR). The model examines two headline indicators:

- the proportion of community care clients who receive direct payments; and - the average size of direct payments, per service user per year.

The first indicator is a proportion, and not an absolute number. The analysis will nevertheless need to control for differences in authority size (measured, for example, by population numbers or total social care expenditure) because larger councils may have greater potential to set in place the support arrangements needed for direct payment users. But focusing on the proportionate take-up of direct payments makes it less likely that we will spuriously pick up associations by virtue of scale effects alone. Our second indicator - the volume of resources allocated on average per recipient - has received little attention in the literature thus far.

\section{Conceptual underpinnings: relevant factors as demand and supply-side elements}

Drawing on theoretical underpinnings successfully applied in research on other aspects of territorial variation (Fernández and Forder, 2002), our statistical model logically organises potential relevant factors into 'demand-side' and 'supply-side' influences. Figure 5 shows how these are related conceptually.

The appeal of the demand and supply distinction as a means of simplification is that it can distinguish between, on the one hand, effects which are more directly subject to conscious prioritisation, and which are reflected on the ground through practices understood by those involved as manifestations of local public policy; and, on the other, those effects which are less amenable to CSSR control. Thus, 


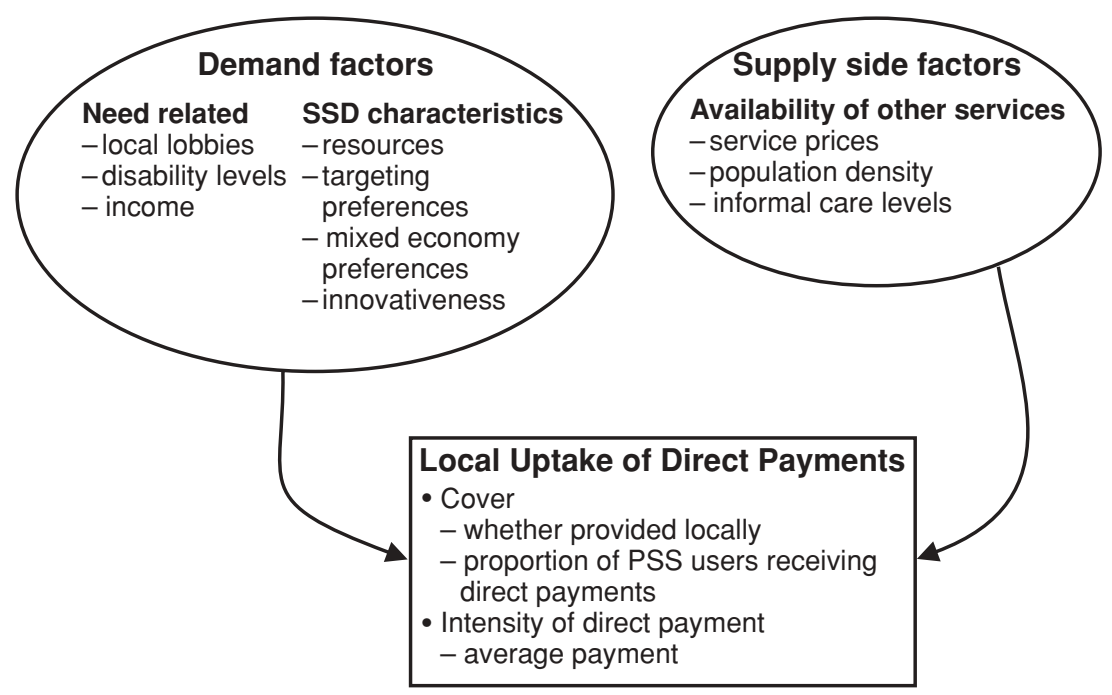

Figure 5. Analysis framework.

on the demand side, we have influences bound up with, and reflected in, the preferences of individual councils. They can be understood as 'public' to the extent they reflect to a significant degree processes of public deliberation; and they are 'policy' factors because they are characterised by a relatively high degree of intention, and reflect conscious choices over options on the part of decision makers (Parsons, 1995: 2-15). We will need to separate two groups of demandside factors: system-wide influences on council demand for public services in general - such as demographic, socio-economic characteristics and political factors - and more social care-specific ingredients, as reflected in social services department priorities. These latter are theoretically nested within and shaped by the more generic factors, but need to be taken into account in their own right for at least three reasons. First, social care policies have to be broadly compatible with corporate policies, but social care actors have a certain degree of autonomy over aspects of decision making (Rhodes, 1988). Social care policies cannot, in other words, be simply read off from local authority policies, but have their own style and developmental momentum. Second, narrow service objectives may have drifted from those that would be suggested by underlying levels of demand over time. For instance, commitments to long-term block contracts may limit the possibilities for changes in services further down the line, and decisions may also reflect the legacy of particular histories between significant external influences such as local voluntary sector groups - and councils. Finally, being closer to the front-end of things, local service priorities are likely to be more powerful predictors of patterns of direct payments utilisation. 
Supply-side effects can be understood as constituting the constraints which policy actors face, and over which they have relatively little direct control, such as resource scarcity and local social care system capacity, as reflected in prevailing cost structures. For example, does the utilisation of direct payments relate to the cost of providing other services, such as the price of residential care? What is the nature of the link to the unit costs of home care, by far the main service purchased by older people through direct payments funds? (Clark et al., 2004). And what are the economic consequences of population density? In addition, account is logically to be taken here of the repercussions of variations in the availability of informal support.

\section{From theoretical relationships to empirical operationalisation}

Local authority service priorities cannot be observed directly. We have therefore used indicators of recorded practice as markers of 'latent' service priorities; resource availability, targeting policies, level of control of service provision, and degree of emphasis on provision of 'responsive' or 'innovative' services are assumed to represent expressions of the underlying preferences of councils towards the promotion of user choice or the balance between community and residential-based care (Davies, 1968).

\section{Data sources and estimation methods}

The main data - collected for three periods, 2000/01, 2001/02 and 2002/03 are summarised in Table 1, together with their sources. We pooled these data, controlling for time period fixed effects by using year dummies. We examined variations for each of the main service user groups in turn: older people, younger disabled people, mental health service users, and people with learning disabilities.

Implementation of the analysis strategy required us to address five particular statistical issues.

(a) Non-normality of dependent variables: To account for the non-normality of the distributions of our two direct payment indicators we used generalised linear modelling (GLM) estimation methods, with the appropriate variance function chosen following the methodology proposed by Manning and Mullahy (2001).

(b) Collinearity between explanatory indicators: It is likely that two or more of the potential explanatory factors are themselves correlated, making it difficult to identify the true impact of each on the direct payments indicators. This is the common problem of multicollinearity. We therefore used an 'instrumental variables' approach (Gujarati, 1988) which explicitly recognises these interconnections. For instance, the indicator of local levels 
TABLE 1. Data sources.

\begin{tabular}{lll}
\hline Category & \multicolumn{1}{c}{ Variable } & \multicolumn{1}{c}{ Source } \\
\hline Service provision & Number of direct payments & RAP forms, DoH \\
& Number of clients of other services & RAP forms, DoH \\
& Residential care utilisation & RS forms, DoH \\
& Home care utilisation & HH forms, DoH \\
& Expenditure in social care services & PSS EX, DoH \\
Local need & Informal support & Census \\
& Health status & Census \\
& Limiting long-standing illness & Census \\
& Deprivations scores & Census \\
& Population profiles & ONS \\
& LA socio-economic classification & ONS \\
& Political control & Electoral commission \\
& Area, Density & ONS \\
& Mortality & ONS \\
& Receipt of SS benefits & DWP \\
& Home care unit costs & PAF forms, DoH \\
Weekly expenditure per residential & PAF forms, DoH \\
placement & \\
& Local wages & New Earnings Survey \\
House prices & Land Registry \\
Local performance & Sastisfaction with services & PAF forms, DoH \\
& Speed of service provision & PAF forms, DoH \\
\hline
\end{tabular}

of service expenditure included in the models was adjusted so that it was no longer related to local need or prices with which it is known to be correlated.

(c) Theoretically relevant but empirically 'insignificant' factors: Identical sets of factors were initially examined for each service user group, but only indicators found to have a statistically significant influence on direct payments were included in the final models in order to simplify the interpretation of the effects (by minimising the risk of multicollinearity) and to prevent loss of precision in the estimates. As a result, the estimated models include different combinations of explanatory factors, and some of the hypothesised factors explored do not appear at all. In particular, we found no relationship between indicators of political control and any of the dependent variables explored.

(d) Small numbers: Because of the very small number of local authorities providing direct payments for people who use mental health services, the indicator of coverage for this group was defined simply in terms of whether or not a local authority provided any level of the service (for other user groups we measured the proportion of all clients), and we estimated the equation with a logistic regression model. For the same reason, the model exploring average payment size was not estimated for mental health users. 
TABLE 2. Factors associated with the proportion of community care clients receiving direct payments: physical disabilities.

\begin{tabular}{llr}
\hline & Coeff & Prob \\
\hline $\begin{array}{l}\text { General health: share of population declaring their } \\
\text { health to be good }\end{array}$ & -0.02 & $<0.01$ \\
$\begin{array}{l}\text { Index of multiple deprivation } \\
\text { Proportion of home care provided in-house }\end{array}$ & -0.03 & $<0.01$ \\
$\begin{array}{l}\text { Proportional physical disability social care expenditure } \\
\text { on residential and nursing care }\end{array}$ & -0.00007 & 0.04 \\
$\begin{array}{l}\text { Population density } \\
\text { Proportion of the population providing informal }\end{array}$ & -0.06 & 0.01 \\
$\quad$ support & -0.05 & 0.03 \\
Year 2001-2002 & & $<0.01$ \\
Year 2002-2003 & 0.13 & 0.44 \\
Constant & 0.60 & $<0.01$ \\
Obs. $=372 \quad$ Pseudo R $\mathrm{R}^{2}=16 \%$ & 15.47 & 0.01 \\
\hline
\end{tabular}

Note: GLM model; Link function: Log, Variance function: Poisson.

(e) Missing values: To prevent biases and to minimise loss of precision, missing values for variables in the analysis (other than for indicators of direct payments) were replaced using multiple imputation procedures. ${ }^{3}$ The results based on the five complete data sets were combined using the NORM software.

\section{Findings}

Tables 2-5 summarise the statistical findings for each service user group in turn with regard to direct payments take-up, and Tables 6-8 summarise the results in relation to the average level of direct payments.

\section{Take-up of direct payments}

\section{Proportion of home care provided in-house}

Other things being equal, local authorities in which a relatively low proportion of home care is provided in-house tend to have relatively high direct payments take-up by older people and people with physical disabilities.

CSSRs with relatively high levels of in-house services often defend this situation with reference to the need to be equipped to meet particularly intense or complex needs which could not be met by local external suppliers. To the extent that we have sought to control separately for needs-related circumstances, this argument might not be relevant here (unless our needs indicators are not fit for purpose; see below). If other justifications for municipal ownership and control of services can be assumed to be secondary, then what we could be seeing here is empirical evidence in support of the salience of the 'protectionist' arguments identified earlier.

\section{CAMBridge JUURNALS}


TABLE 3. Factors associated with the proportion of community care clients receiving direct payments: older people.

\begin{tabular}{lcr}
\hline & Coeff & Prob \\
\hline Proportion of the population aged 85 plus & 58.56 & 0.01 \\
Area of the local authority & $1.8 \mathrm{E}-04$ & $<0.01$ \\
Rate of receipt of direct payments among physically disabled, & 2.93 & $<0.01$ \\
$\quad$ controlling for local demand and supply factors & & \\
Proportion of home care provided in-house & $-1.3 \mathrm{E}-02$ & 0.03 \\
Expenditure on social care for older people per population & $1.2 \mathrm{E}-03$ & $<0.01$ \\
$\quad$ 65 plus & & \\
Ratio of older people assessed by social care services to & $-1.0 \mathrm{E}-02$ & $<0.01$ \\
$\quad$ population 65 plus & & \\
Year 2001-2002 & 0.39 & 0.20 \\
Year 2002-2003 & 0.45 & 0.10 \\
Constant & -8.21 & $<0.01$ \\
Obs. $=383 \quad$ Pseudo $\mathrm{R}^{2}=18 \%$ & & \\
\hline
\end{tabular}

Note: GLM model; Link function: Log, Variance function: Poisson.

TABLE 4. Factors associated with the proportion of community care clients receiving direct payments: learning disabilities.

\begin{tabular}{lcc}
\hline & Coeff & Prob \\
\hline $\begin{array}{l}\text { General health: share of population declaring their health to } \\
\quad \text { be not good }\end{array}$ & -0.03 & $<0.01$ \\
$\begin{array}{l}\text { Standardised mortality rate } \\
\text { Rate of receipt of direct payments among physically disabled, } \\
\quad \text { controlling for local demand and supply factors }\end{array}$ & 0.04 & 0.03 \\
$\begin{array}{l}\text { Proportional learning disability social care expenditure on } \\
\quad \text { residential and nursing care }\end{array}$ & -2.05 & 0.01 \\
$\begin{array}{l}\text { Proportion of the population receiving intensive home care } \\
\text { Population density }\end{array}$ & 0.04 & 0.01 \\
Average gross weekly expenditure on supporting adults with & -0.15 & 0.01 \\
$\quad$ learning disabilities in residential and nursing care & -0.001 & 0.06 \\
Year 2001-2002 & & 0.06 \\
Year 2002-2003 & 1.06 & 0.03 \\
Constant & 1.97 & $<0.01$ \\
Obs. $=354 \quad$ Pseudo R ${ }^{2}=19 \%$ & -7.04 & $<0.01$ \\
\hline
\end{tabular}

Note: GLM model; Link function: Log, Variance function: Poisson.

There could also be a link to risk-aversion, because the original decision to maintain extensive in-house services could already be suggestive of resistance to the loss of control over services. CSSRs providing a significant level of services inhouse also have more to lose, because the loss of control in allowing users to move away from dependence on in-house services by direct payments is proportionately greater than the loss of control in moving from already externalised services to 
TABLE 5. Factors associated with whether local authorities provide direct payments for mental health clients.

\begin{tabular}{|c|c|c|}
\hline & Coeff & Prob \\
\hline Index of multiple deprivation & $8.4 \mathrm{E}-\mathrm{O} 2$ & $<0.01$ \\
\hline Area of the local authority & $5.1 \mathrm{E}-\mathrm{O} 4$ & $<0.01$ \\
\hline Local authority population & $3.1 \mathrm{E}-\mathrm{O} 3$ & $<0.01$ \\
\hline $\begin{array}{l}\text { Ratio of number of mental health clients } \\
\text { receiving services to population } 18-64\end{array}$ & 0.14 & 0.04 \\
\hline $\begin{array}{l}\text { Proportion of the population providing } \\
\text { informal support }\end{array}$ & $-4.9 \mathrm{E}-02$ & 0.04 \\
\hline Year 2001-2002 & 0.25 & 0.73 \\
\hline Year 2002-2003 & 2.76 & 0.02 \\
\hline Constant & -6.66 & 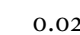 \\
\hline Obs. $=356 \quad$ Pseudo $\mathrm{R}^{2}=25 \%$ & & \\
\hline
\end{tabular}

Logistic model.

TABLE 6. Factors associated with the average intensity of direct payments for physical disability clients.

\begin{tabular}{|c|c|c|}
\hline & Coeff & Prob \\
\hline $\begin{array}{l}\text { Expenditure on social care for physically disabled, controlling for } \\
\text { local demand and supply factors }\end{array}$ & $4.8 \mathrm{E}-05$ & 0.01 \\
\hline $\begin{array}{l}\text { Adults aged 18-64 with physical disabilities helped to live at home } \\
\text { per 1,000 population aged 18-64 }\end{array}$ & $4.2 \mathrm{E}-\mathrm{O} 2$ & 0.03 \\
\hline Average gross hourly cost for home help/care & $7.9 \mathrm{E}-02$ & $<0.01$ \\
\hline $\begin{array}{l}\text { Average gross weekly expenditure per person on supporting adults } \\
\text { with physical disabilities in residential and nursing care }\end{array}$ & $1.2 \mathrm{E}-\mathrm{O} 3$ & $<0.01$ \\
\hline $\begin{array}{l}\text { Number of direct payments for physically disabled per } \\
\text { population } 18-64\end{array}$ & -0.72 & 0.01 \\
\hline Year 2001-2002 & -0.12 & 0.23 \\
\hline Year 2002-2003 & -0.23 & 0.02 \\
\hline Constant & 0.65 & 0.04 \\
\hline Obs. $=301 \quad$ Pseudo $\mathrm{R}^{2}=23 \%$ & & \\
\hline
\end{tabular}

Note: GLM model; Link function: Log, Variance function: Gamma.

TABLE 7. Factors associated with the average intensity of direct payments for older people.

\begin{tabular}{lcr}
\hline & Coeff & Prob \\
\hline Proportional expenditure on supported accommodation & 12.39 & $<0.01$ \\
Average gross hourly cost for home help/care & $5.5 \mathrm{E}-02$ & 0.08 \\
Proportion of over 65s receiving direct payments & -0.57 & 0.02 \\
Year 2001-2002 & -0.53 & 0.05 \\
Year 2002-2003 & -0.36 & 0.15 \\
Constant & 1.49 & $<0.01$ \\
Obs. $=119 \quad$ Pseudo $\mathrm{R}^{2}=16 \%$ & & \\
\hline
\end{tabular}

Note: GLM model; Link function: Log, Variance function: Poisson. 
TABLE 8. Factors associated with the average intensity of direct payments for learning disability clients.

\begin{tabular}{llr}
\hline & Coeff & Prob \\
\hline $\begin{array}{l}\text { Expenditure on social care for learning disabled, controlling } \\
\quad \text { for local demand and supply factors }\end{array}$ & $2.5 \mathrm{E}-05$ & 0.15 \\
$\begin{array}{l}\text { Proportional learning disability social care expenditure on } \\
\quad \text { residential and nursing care }\end{array}$ & -1.14 & 0.01 \\
$\begin{array}{l}\text { Number of direct payments for learning disabled per } \\
\quad \text { population 18-64 }\end{array}$ & -7.48 & $<0.01$ \\
$\begin{array}{l}\text { Year 2001-2002 } \\
\text { Year 2002-2003 }\end{array}$ & $9.9 \mathrm{E}-02$ & 0.78 \\
$\begin{array}{l}\text { Constant } \\
\text { Obs. }=69 \quad \text { Pseudo } \mathrm{R}^{2}=18 \%\end{array}$ & 0.18 & 0.51 \\
\hline
\end{tabular}

Note: GLM model; Link function: Log, Variance function: Poisson.

direct payments. In the latter case, CSSRs have already relinquished direct control rights over care workers' pay and conditions, and the capacity to shape service content by hierarchical control; so, while the move to direct payments of course necessarily represents a major change, there is less distance to travel when direct payment options are put in place.

In addition, the statistical relationship may suggest a paucity of internal entrepreneurship and external connectedness. To the extent that a significant inhouse capacity implies rigidity in job roles and responsibilities, such authorities may offer a less hospitable environment for the championing of new policies and practices. Moreover, if direct control of the service delivery role was seen to indicate insensitivity to externally expressed demands, it could be making such councils less open to the advocacy efforts of supportive local user groups and voluntary organisations.

Dysfunctional hierarchical governance arrangements may also make it generally harder to exchange evidence and argument about new and effective policies, so that it could be more difficult for local authorities who have retained significant in-house capacity to cascade new policies and ideas down to the front line. This would accord with the belief that traditional bureaucracy may be less able to react to potentially advantageous and desirable direct payment service options.

\section{Residential care expenditure}

For people with physical disabilities and learning difficulties, the statistical analyses suggest that take-up of direct payments is low in authorities with a high ratio of traditional residential care expenditure compared to (other forms of) community care expenditure. Because of the 'instrumental variables' approach taken to address the problem of correlated explanatory factors, this greater 
utilisation of residential care - just as with the in-house case already discussed should not be attributable to higher levels of need for residential as opposed to other forms of community care (Harwood, 2004). Again, the themes identified earlier help us to interpret this negative link. The willingness and ability to adopt direct payments may be constrained in CCSRs with high proportional residential care expenditure by the need to commit resources to sustain existing patterns of service, at least in the short term. The effect may also signal relatively lesser commitments at the local level to the development of forms of care to sustain service users in the community.

\section{Population density}

The take-up of direct payments for people with physical and learning disabilities is greater in areas with lower population density. Direct payments may be more likely in circumstances where the provision of traditional services is difficult: travelling between service users is more demanding in time and resources when populations are sparse. A caveat in this interpretation is that population density is highly correlated with rurality. As such, the effect may therefore relate to characteristics specific to shire counties, for example.

\section{Informal care levels}

The higher the proportion of the local population providing informal care, the lower the take-up of direct payments by people with physical disabilities and people who use mental health services. In a key sense, for one type of informal care this goes with the grain of national policy, since co-resident carers are not (in normal circumstances) eligible for direct payments. At the same time, it is possible that some of this effect reflects unintended consequences: it could be that the observed pattern relates to the withdrawal of informal care support following the establishment of the scheme. However, given the relatively low take-up rates, this effect is likely to be small in size.

\section{Direct payments for older people: synergies and scale effects}

The case of direct payments for older people is interesting not only because of the potentially vast number of users, but because of the relatively late arrival of the policy as a national principle (in 2000). Interestingly, the English data suggest that local authorities with relatively high take-up of direct payments by people with physical disabilities have tended to have high prevalence with respect to older people too.

This finding, also identified for learning disabilities, is an old theme with a new twist. The literature has long emphasised that direct payment policy commitments beget further policy commitments: a kind of micro-level policy legacy effect (Pierson, 1994). This has been taken to mean that locales with traditions of support in relation to younger people with disabilities from 
the 1990 - and even in the 1980s, via local indirect payment or third-party schemes - have tended to be those where the policy has taken off most strongly in the current decade. What we are witnessing here is rather a cross-service user group effect.

These effects may be reflecting 'economies of scope' over time, in the sense that successful operation within the 'pioneer' client group seems to be producing learning effects for the late-coming group. But the statistical findings also point to scale effects. The coefficients in Table 3 indicate that larger and wealthier local authorities tend to have higher take-up. As far as the latter is concerned, clearly such authorities are better positioned to be appropriately generous with packages - in other words, potentially reflecting the fifth theme (resource scarcity) we identified from the literature. As far as the size attribute is concerned, this could be consistent with our earlier suggestion that the costs of setting up and embedding direct payments may be significant, and should not be underestimated (not least because of the multiplicity of actors and tiers of the state involved). Larger authorities' greater capacity to move to a scale of operation which can spread these fixed costs and thus bring down average costs would seem to be relevant.

Voluntaristic demand-side pressures may have also played a greater role. The structure of the voluntary sector for older people seems to be more loosely coupled, and to involve a greater amount of fragmentation than the sector relating to other client groups, where national organisations seem relatively dominant (Kendall, 2003). Under these circumstances, what happens in localities will likely rely more on the capacity of local voluntary bodies than on top-down impetus from national organisations. If large local authorities are more likely to create the conditions under which efficacious older people-specific voluntary sectors can flourish, direct payments uptake could be higher because of the more effective advocacy of voluntary bodies.

Local authorities that assess greater proportions of their older population aged over 64 provide relatively fewer of their clients with direct payments, other things being equal. This finding conforms with one of the hypotheses made in the introductory section and just mentioned again above: authorities serving greater proportions of their communities are likely to provide less intensive packages of care and as a consequence may not reach the necessary level of care required to make direct payments attractive to service users. Furthermore, our ongoing qualitative research suggests that care managers may assume that the trade-off between responsibilities and benefits is too great for small packages of care and may reflect this assumption when offering direct payments, making them appear less attractive.

Given the documented pivotal role performed by local authorities in mediating demand for direct payments (Commission for Social Care Inspection, 2004a; Carmichael and Brown, 2002), combined with the reported desire for 
direct payments (albeit among those of near retirement age) (Commission for Social Care Inspection, 2004b), our results suggest that authorities which assess and provide for relatively greater proportions of their older population offer more limited opportunities for older people to exercise choice in the services they wish to receive.

\section{Puzzling results on health and deprivation}

Looking across the service user groups, perhaps the least expected of the findings in Tables 2 to 5 are the different directions of the effects of population health, and of multiple deprivation. In the case of people with physical disabilities, good population health is linked to relatively low direct payments take-up, whereas for people with learning disabilities the relationship is reversed. Multiple deprivation also has significant effects in two different directions: lower uptake for people with physical disabilities in multiply deprived areas, but the opposite for people who use mental health services.

It may be helpful to reach for our earlier discussion to make sense of these patterns: relative local voluntary/user sector capacity and/or the local availability of policy entrepreneurship to convert otherwise latent need into concrete policy action. There is certainly no automatic conversion of either need on the one hand, or resources on the other, into take-up, but a more contingent relationship is revealed by the data. So, in the case of people with physical disabilities for example, direct payments take-up seems to be inversely related to local need. In such contexts, especially where deprivation and social exclusion are at stake, it could be that front-line professionals are more reluctant to embrace direct payments on the basis that the exposure of vulnerable clients to the local market could be seen as unsafe. Locales with these attributes might also be less likely to be populated either by local voluntary bodies promoting this policy and willing to support its implementation, because such organisations tend to flourish more in affluent areas (Wolpert, 1988).

A link between geography and ethnicity could additionally be reinforcing this relationship. People from black and ethnic minority groups are disproportionately located in deprived areas and these groups exhibit especially low levels of engagement with direct payments. Consequently, there may be cultural reinforcement effects at play (Vernon, 2002). Constraints on the willingness or ability of any white-led voluntary groups to reach out to these groups (Wilding et al., 2004) could also be a limiting factor.

Where the opposite relationship prevails - as with mental health service users, for example - the combination of local activism and policy entrepreneurship could be more than offsetting such barriers and constraints. This might happen in a number of ways. First, front-line professionals in relatively blighted authorities might actually recognise that local traditional social services are themselves correspondingly weak, so that direct payments actually constitute an escape 
route from otherwise poor services. The implicit judgement would be that local in-house or contracted services are so limited that the hazards of control loss in a difficult socio-economic environment associated with going for direct payments is more than offset by that approach's advantages. Second, the environment of deprivation could be triggering extra resources from state budgets, such as government area-based initiatives. The involvement by outside national voluntary bodies or federations, ${ }^{4}$ stepping in where 'home-grown' activism and support is weak precisely because levels of need are perceived to be high, could be relevant. In this way, a combination of local and national efforts by the state and the voluntary sector could conceivably be creating the momentum for higher take-up, despite the obstacles associated with deprivation.

\section{Direct payments: average payment package size}

It is harder to link the discussion of average payment package size to the themes in the literature, because previous research and policy commentary have focused heavily on take-up rather than volume or intensity of activity. Tables 6 to 8 summarise the results of the statistical models exploring correlations between characteristics of local authorities and average direct payment package size for people with physical disabilities, older people and people with learning disabilities respectively. Although generally fewer associations with CSSR characteristics were apparent than in the analyses looking at take-up rates, the effects are quite consistent across groups.

After adjusting for other factors, the results suggest that there has been a reduction in recent years in the average size of direct payments in the case of older people, and for people with physical disabilities. Otherwise, four general types of effects are identified in the results: three relating to demand-side indicators, and one a supply-side effect.

One demand-related effect relates to levels of expenditure on social care for individual service user groups. For the physical disability and learning disability groups, councils that spent relatively higher levels of resources per community care client provided on average higher levels of direct payments for those groups. Given the nature of the indicator (as with the take-up model, using 'instrumental variables' to remove the effect on expenditure of local levels of need and of differences in input prices), this suggests a correlation between the prioritisation given by authorities to social care for individual client groups and their willingness and/or ability to provide more intensive direct payment packages. ${ }^{5}$ Furthermore, there are greater incentives for individuals on more intensive packages of care to take-up direct payments because these individuals also have access to disabilityrelated benefits (unavailable to people on very low-level packages). Younger physically disabled people receiving packages costing more than $\mathfrak{E} 200$ per week also have access to the Independent Living Fund (ILF). Individuals in receipt of disability-related benefits and the ILF have free rein to use these resources 
as they wish, to top up their direct payment funds, enabling them to purchase care at a more intensive level or pay higher prices or secure care which provides even greater flexibility in their daily lives. Unlike direct payments, use of these resources is not monitored.

Second, the results reveal a strong negative relationship between the per capita number of recipients of direct payments and the size of the average direct payment package. This echoes the more general tension felt in recent years across the broad community care spectrum between providing less care to many and targeting greater resources on the few. It is difficult to judge the appropriateness of the balance between concentrating high-intensity direct payment packages and achieving greater numbers of low-intensity care packages, since this requires evidence on outcomes collected at the individual level of the kind that is not available in the UK. Of particular importance will be shifts in the mixes of care services purchased through direct payments, as well as changes in the nature of individual services as they become more responsive to the preferences of users.

Third, we see that CSSRs that concentrated more resources on communitybased care services tended to provide more intensive average direct payment packages, other things being equal. A local authority's strength of preference towards promoting independent living thus appears to translate into the provision of more intensive direct payments.

Local supply conditions were reflected in average package size: the average intensity of direct payment was positively related to the average unit costs of home care and residential care services. Given the nature of the indicators of local supply conditions (local house prices and wages), it is difficult to gauge the extent to which local authorities fully account for variation in unit costs of services. This is an important finding in the current policy debate because of the criticism that local authorities are setting hourly rates which, given need, are insufficient to fully fund the assessed packages of care. The quantitative result obtained here is at least suggestive that this criticism may have been overstated.

\section{Conclusion}

This article has brought together evidence and argument developed in the burgeoning direct payments academic and policy literatures with an empirical investigation of patterns of variation in take-up and average payment amount in order to deepen our understanding of one aspect of the central policy theme of choice (Department of Health, 2005). Statistical modelling generally requires parsimony in order to ensure analytic tractability, and to allow for methodological operationalisation. It necessarily focuses on those elements which are amenable to quantification. It cannot capture all potentially relevant influences considered in the direct payments or more general social services variation literatures. Nevertheless, we have been able to examine a number of implementation 
hypotheses with data for all English councils with social services responsibility over a three-year period.

Although we need to emphasise, therefore, that the research presented here represents some first steps in a longer process, it is also important to conclude by underlining that our findings already allow us to be confident in making certain claims about the nature of the direct payments process. This includes a range of claims which have been made frequently in existing small-scale research, but which had previously lacked a substantive and systematic evidence base with which to substantiate them. While these lack the specificity of falsifiable hypotheses and do not allow us to determine causality, they suggest empirical regularities which future work of this kind should keep in mind as it moves forward.

Other research on direct payments will complement this quantitative evidence. Qualitative case studies gathering evidence on the perspectives and behaviours of all relevant proximate stakeholders, including users, their informal carers, key professionals (in particular, care managers), and employees (personal assistants) will allow implementation issues to be explored in more detail, of course. But such evidence would also inform the refinement of our macro-level quantitative model in terms of both specification and interpretation.

Our analysis confirms that direct payment activity is significantly shaped by attributes of local social care subsystems. As implicitly anticipated by other research but demonstrated nationally for the first time by our results, direct payments policy implementation activity is not randomly distributed, but systematically shaped by the features of localities captured in our models. Our substantive findings reveal that the public policy stance of CSSRs and features of the local landscape beyond their control both matter. In economic jargon, we witness a mixture of both demand and supply-side influences, whether we consider take-up or intensity of direct payment activity.

Second, we have shown that some influences are shared across service user groups, while others have more specific relevance. Most prior research has concentrated on developing evidence and argument for specific service user groups, while the work reported here draws attention to influences that cut across them. In addition, perhaps one of our most interesting single findings is the existence of a direct link between the take-up of the scheme for people with physical disabilities and its penetration with regard to older people. The policy of direct payments at the local level does not appear to evolve autonomously within different service user groups, but is shaped by the wider legacy of policy that prevails across social care as a whole.

Efforts to increase direct payment activity locally which concentrate on the application of uniform standards and incentives across the country are unlikely to represent an efficient targeting of policy resources. Rather, because the extent to which the policy is adopted at this level seems to reflect particular policy legacies 
and subsystem configurations, support will need to be developed or tailored on a case-by-case basis. The Department of Health's initiation of a special development fund implicitly recognises this unevenness in local systems' capacities to respond to national policy, and there are likely to be major differences in the nature and scale of the challenges faced by those seeking to put the fund into practice.

Finally, as policy implementation unfolds, it will be important to bear in mind that no single actor or institution is likely to be able to claim credit for success - or take blame for failures. CSSRs undoubtedly discharge a fundamental role in this process; their nodal positioning in subsystems at the local level means that their policy approach is central to success. Our results indicate a significant influence of local authority-mediated demand-side factors. Hence, among other effects, take-up was found to be higher in CSSRs with lower relative levels of in-house home care provision, and lower relative values of residential care expenditures. At the same time, as our interpretation of the link between need and take-up tried to draw out, much also depends on the strength of local policy initiative, and voluntary sector mobilisation. Last and crucially, some characteristics of local supply that have a bearing on this policy are essentially beyond the direct control of local authorities. Factors such as population density and informal sector capacity vary significantly, meaning that the cost structure of policy implementation differs from place to place. Exercises in performance monitoring and research will need to recognise the extent to which such factors place limits on a local authority's policy choices, regardless of the degree of policy commitment.

\section{Notes}

1 This section has benefited particularly from a working paper by Perri 6 (2005), written as part of the Department of Health's MASC-funded research project on direct payments. A range of references to the 'trade press', commentaries, and academic articles are included there. Other relevant studies have come to fruition since the review, including the independent research published in 2004 included in the references at the end of this paper; and inspectorate reports (Social Services Inspectorate, 2003; Commission for Social Care Inspection, 2004a) which tend to reproduce these themes.

2 This representation, while complex, simplifies at least two further sources of variegation within the state which the literature has identified as relevant to direct payments. First, it underplays the range of central government agencies involved, especially at the implementation stage: most obviously, both central government social security agencies and the Inland Revenue have important roles to play. Second, at the local government level, it does not capture the extent to which the organisation of the commissioning function depends heavily, inter alia, upon relations between the council at the corporate level, its finance department and the social services department. Commissioning is also characterised by internal differentiation in terms of service user groups, forms of care and support as well as standard management and bureaucratic functionality.

3 The approach follows the multivariate mixed effects model described in Schafer (1997) and Little and Rubin (1987). In addition, given the non-monotone nature of the pattern of missing values in the data, the imputation process was carried out using Markov chain Monte Carlo. 
Starting values for the Markov chain were estimated with the expectation maximisation algorithm. Five different imputed values were derived using the statistical package NORM, version 2.03 (Schafer, 1999). Rubin (1996) and Schafer (1997) have noted how, when the proportion of data missing is relatively low (as in the present case), five imputations suffice to achieve efficient estimations of changes in the standard errors of parameters. Imputed values were restricted to the observed range of values in the data.

4 Of the range of voluntary groups with a stake in direct payments, the literature tends to emphasise that it is the presence of strong user groups in general, and Centres for Independent/Integrated Living in particular, which are most committed to these policies (Barnes, 2004; Riddell et al., 2005).

5 This effect is potentially endogenous: direct payment packages may be more intensive as a result of increases in social care spending, but social care spending itself may increase because direct payment packages are more intensive. However, given the very small proportion of social care expenditure related to direct payments, the endogeneity issue can be largely ignored, and social care budgets taken as exogenously determined.

\section{References}

6, P. (2005), 'The implementation of direct payments: independent variables and hypotheses from the literature', Nottingham Trent University.

Barnes, C. (2004), 'Independent living, politics and implications for the 21st century', mimeo, University of Leeds.

Barnes, C., Jolly, D., Mercer, G., Pearson, C., Priestley, M. and Riddell, S. (2004), 'Devolving direct payments: a review of policy development in the UK', paper presented at the Disability Studies Conference, University of Lancaster.

Carmichael, A. and Brown, L. (2002), 'The future challenge of direct payments', Disability and Society, 17: 7, 797-808.

Clark, H., Gough, H. and Macfarlane, A. (2004), It Pays Dividends: Direct Payments and Older People, Bristol: Policy Press.

Commission for Social Care Inspection (2004a), Direct Payments: What are the Barriers? London: Commission for Social Care Inspection.

Commission for Social Care Inspection (2004b), When I Get Older: What People Want From Social Care Services and Inspections As They Get Older, London: Commission for Social Care Inspection.

Davies, B. (1968), Social Needs and Resources in Local Services, London: Michael Joseph.

Dawson, C. (2000), Independent Successes: Implementing Direct Payments, York: Joseph Rowntree Foundation.

Department of Health (2005), 'Community Care Statistics 2003-04: referrals, assessments and packages of care, England - national summary', http://www.dh.gov.uk/assetRoot/ 04/09/80/58/04098058.pdf

Department of Health (2005), Independence, Well-Being and Choice: Our Vision for the Future of Social Care for Adults in England, Cm 6499, London: HMSO.

Direct Payments Scotland (2003), 'Direct payments finance project report', a report by Direct Payments Scotland, http://www.dpscotland.org.uk/

Fernández, J. L. and Forder, J. (2002), 'The importance of social care in achieving an efficient health care system: Impact on hospital delay discharge rates', LSE Health and Social Care Discussion Papers 7.

Glasby, J. (2004), 'Discharging responsibilities? Delayed hospital discharges and the health and social care divide', Journal of Social Policy, 33: 4, 593-604.

Glasby, J. and Littlechild, R. (2002), Social Work and Direct Payments, Bristol: Policy Press.

Glendinning, C., Halliwell, S., Jacobs, S., Rummery, K. and Tyrer, J. (20ooa), 'Bridging the gap: using direct payments to purchase integrated care', Health and Social Care in the Community, 8: 3, 192-200. 
Glendinning, C., Halliwell, S., Jacobs, S., Rummery, K. and Tyrer, J. (20oob), 'New kinds of care, new kinds of relationship: how purchasing affects relationships in giving and receiving personal assistance', Health and Social Care in the Community, 8: 3, 201-211.

Gujarati, D. N. (1988), Basic Econometrics (2nd Edition), London: McGraw-Hill.

Harris, J. (1999), 'State social work and social citizenship in Britain: from clientelism to consumerism', British Journal of Social Work, 29: 915-937.

Harwood, R. H. (2004), 'Do we still need care homes? Editorial', Age and Ageing, 33: 529-530.

Hasler, F. and Stewart, A. (2004a), 'Developing direct payments in the North East of England', Findings, York: Joseph Rowntree.

Hasler, F. and Stewart, A. (2004b), Making Direct Payments Work, York: Joseph Rowntree.

Hasler, F., Campbell, J. and Zarb, G. (2000), 'Implementation of the community care (Direct Payments) Act', Findings, York: Joseph Rowntree.

Kendall, J. (2003) The Voluntary Sector: Comparative Perspectives in the UK, London: Routledge.

Kodner, D. L. (2003), 'Consumer-directed services: lessons and implications for integrated systems of care', International Journal of Integrated Care, 3: 1568-4156.

Lewis, J. (2001), 'Older people and the health-social care boundary in the UK: half a century of hidden policy conflict', Social Policy and Administration, 35: 4, 343-359.

Little, R. J. A. and Rubin, D. B. (1987), Statistical Analysis with Missing Data, New York: John Wiley \& Sons.

Manning, W. G. and Mullahy, J. (2001), 'Estimating log models: to transform or not to transform?', Journal of Health Economics, 20: 461-494.

Parsons, W. W. (1995), Public Policy, Aldershot: Edward Elgar.

Pierson, P. (1994), Dismantling the Welfare State? Reagan, Thatcher and the Politics of Retrenchment, Cambridge/New York: Cambridge University Press.

Rhodes, R. A. W. (1988), Beyond Westminster and Whitehall: The Sub-central Governments of Britain, London: Unwin Hyman.

Riddell, S., Pearson, C., Jolly, D., Barnes, C., Priestly, M. and Mercer, G. (2005), 'The development of direct payments in the UK: implications for social justice', Journal of Social Policy and Society, 4: 1, 75-86.

Rubin, D. B. (1996), 'Multiple imputation after 18+ years', Journal of the American Statistical Association, 91: 473-489.

Schafer, J. L. (1997), Analysis of Incomplete Multivariate Data, New York: Chapman \& Hall.

Schafer, J. L. (1999), 'NORM: multiple imputation of incomplete multivariate data under a normal model', version 2, Software for Windows 95/98/NT, available from http://www.stat.psu.edu/ jls/misoftwa.html.

Social Services Inspectorate (2003), Modern Social Services a Commitment to the Future: The 12th Annual Report of the Chief Inspector of Social Services 2002-2003, London: Department of Health.

Spandler, H. (2004), 'Friend or foe? Towards a critical assessment of direct payments', Critical Social Policy, 24: 2, 187-209.

Ungerson, C. (2004), 'Whose empowerment and independence? A cross-national perspective on "cash for care" schemes', Ageing and Society, 24: 2, 189-212.

Vernon, A. (2002), User Defined Outcomes of Community Care for Asian Disabled People, Bristol: Policy Press.

Wilding, K., Collins, G., Jochum, V. and Wainright, S. (2004), The UK Voluntary Sector Alamanac 2004 (5th Edition), London: NCVO Publications.

Wolpert, J. (1988), 'The geography of generosity: metropolitan disparities in donations and support for amenities', Association of American Geographers, 78: 665-679.

Zarb, G. and Nadash, P. (1994), 'Cashing in on independence: comparing the costs and benefits of cash and services for meeting disabled people's support needs', BCODP/PSI, Derby. 